\title{
03 THE MAGNITUDE AND CONTEXTUAL CIRCUMSTANCES OF CHILDHOOD (0-14 YEARS) PEDESTRIAN FATALITIES IN SOUTH AFRICAN CITIES
}

doi:10.1136/injuryprev-2012-040590v.3

${ }^{1}$ Bulbulia Samed, ${ }^{2}$ Vanniekerk Ashley, ${ }^{1}$ Seedat Mohammed, ${ }^{2}$ Donson Hilton. ${ }^{1}$ University of South Africa, Institute for Social and Health Sciences, Johannesburg, South Africa; ${ }^{2}$ Medical Research Council \& University of South Africa Safety \& Peace Promotion Research Unit, Cape Town, South Africa

Background Road traffic injuries continue to manifest as a contributor to the global burden of disease, and road deaths in poor countries are predicted to rise by $80 \%$ by 2020 . South Africa's road traffic crisis is of national concern, with pedestrians accounting for about $43 \%$ of all traffic-related fatalities (NDOT 2006). However there is a paucity of studies on the magnitude and contextual circumstances of pedestrian fatalities that can offer evidence for intervention and prevention strategies, especially growing children who are a vulnerable group.

Aim To understand the magnitude, categories and circumstances in childhood pedestrian fatalities (0-14-year-olds) across several South African cities.

Materials and Methods This is a register-based cross-sectional study using fatal injury data from the National Injury Mortality Surveillance System (NIMSS) for 2001-2005). The years chosen for this study are the most recent for which multi-city level data is available. A cluster analysis was performed on each of the datasets from the four cities. Pedestrian fatalities are classified into specific categories to determine whether and how the categories yielded for the four cities differ with respect to age, gender, and event characteristics.

Results and Conclusions Results reflect that pedestrian fatalities are primarily concentrated in the 5-9 years group, followed by the 0 4 years and 10-14 years respectively for most of the major cities. Childhood pedestrian fatalities predominantly occurred before school, after school and early evenings, over weekends and national holidays. Implications for prevention are also highlighted by way of conclusion. 